\title{
The future survival of African elephants: implications for conservation
}
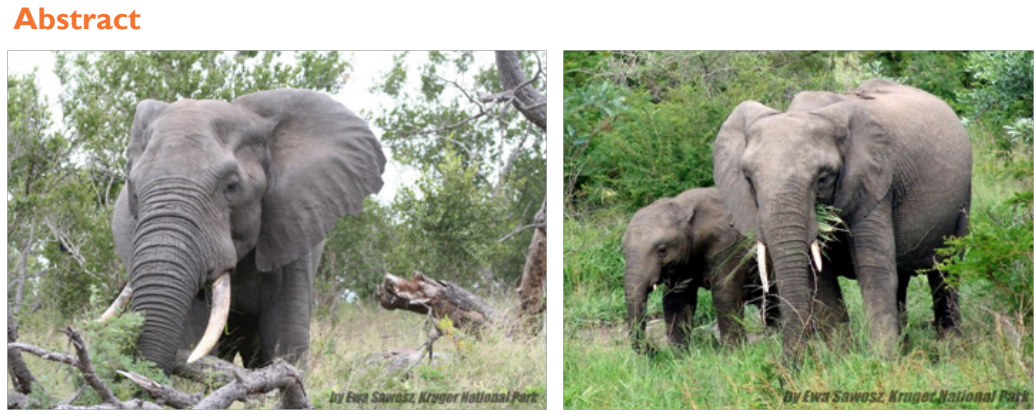

In 2007 the elephant population in Africa was estimated at between 470,000 and 690,000 . However, this population is rapidly decreasing. Today, African elephants are highly endangered and are listed as 'vulnerable' on the International Union for Conservation of Nature Red List. In this review, we outline the major factors affecting the future survival of elephants. We identify elephant poaching in Central Africa as the primary cause of elephants' decline, and this issue has duly received the majority of attention from conservationists and policy-makers. However, poaching is not the only factor: climate change, habitat loss, and human-elephant conflict also have an adverse impact, and all have received relatively little attention due to the predominant focus on poaching.

Keywords: Loxodonta Africana, elephants, conservation, poaching, extinction
Volume 3 Issue 5 - 2018

\author{
Jabulani Nkululeko Ngcobo, ${ }^{1,2}$ Tshimangadzo \\ Lucky Nedambale,' Khathutshelo Agree \\ Nephawe,' Ewa Sawosz, ${ }^{2}$ André Chwalibog ${ }^{2,3}$ \\ 'Department of Animal Sciences, Tshwane University of \\ Technology, South Africa \\ 2Department of Animal Nutrition and Biotechnology, Warsaw \\ University of Life Sciences, Poland \\ ${ }^{3}$ Department of Veterinary and Animal Sciences, University of \\ Copenhagen, Denmark
}

\begin{abstract}
Correspondence: André Chwalibog, Department of Veterinary and Animal Sciences, University of Copenhagen, Groennegaardsvej 3, 1870 Frederiksberg, Denmark, Tel +4540
\end{abstract} 9635 73, Email ach@sund.ku.dk

Received: October 05, 2018 | Published: October 09, 2018

\section{Introduction}

African elephants (Loxodonta Africana) comprise two subspecies: the savanna elephant (Loxodonta Africana) and forest elephant (Loxodonta Africana cyclotis). ${ }^{1}$ These animals are found across Sub-

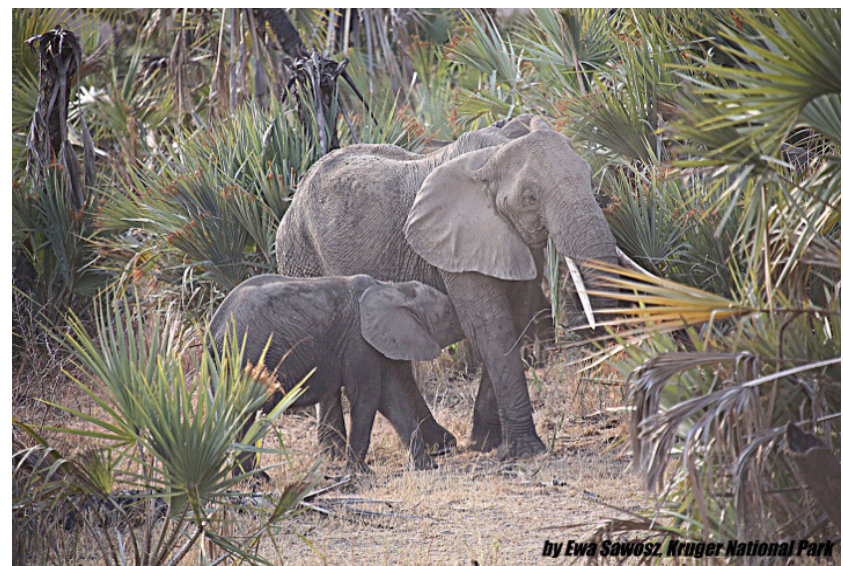

Southern Africa hosts the majority $( \pm 55 \%)$ of the continent's elephant population; Eastern Africa holds $\pm 28 \%$, while Central Africa includes $\pm 16 \%$, and the remaining $\pm 2 \%$ are found in Western Africa (Figure 1). Management strategies are challenging. ${ }^{3}$ For instance, in Western Africa, human population increase and the consequent growth in human-elephant conflict (HEC) has emerged as a highly pertinent issue, to the extent that fewer elephants can be found in Western Africa than in other regions. ${ }^{3,4}$
Saharan Africa, inhabiting swamp forests, savannas and desert. ${ }^{2}$ Savanna elephants live in Eastern and Southern Africa, whereas forest elephants are predominantly found in Central Africa. ${ }^{3,4}$ Moreover, both savanna and forests elephants can be found in small numbers in Western Africa, although their taxonomic status remains undefined.

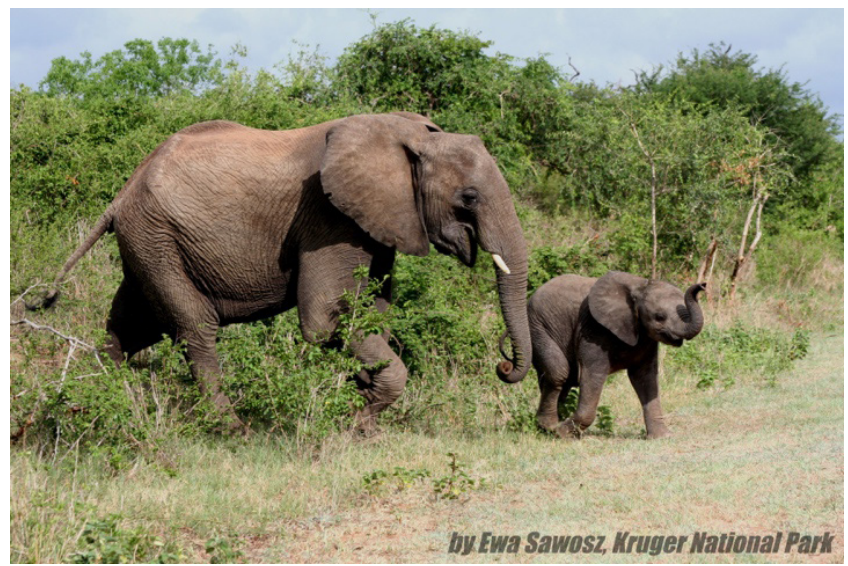

In 2007, Africa's elephant population was estimated at between 470,000 and $690,000 .{ }^{3}$ However, these figures declined by 144,000 by 2014 and have continued shrinking by $8 \%$ every year (Figure 2 ). ${ }^{1}$ Between 2010 and 2012, \pm 100000 elephants were killed. ${ }^{5}$ A principal cause of the killing constituted illegal poaching and the trade of wildlife products, especially ivory. ${ }^{6,7}$ Elephant poaching for ivory is most reported in Central Africa, ${ }^{8}$ the largest amount in Tanzania. ${ }^{7}$ 


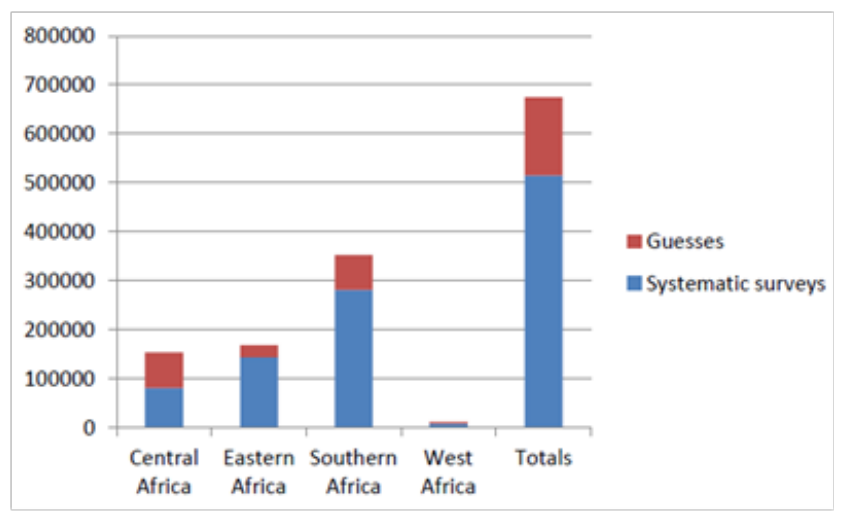

Figure I Elephant population in African regions (Adopted from Nelleman C et al., $\left.{ }^{2}\right)$.

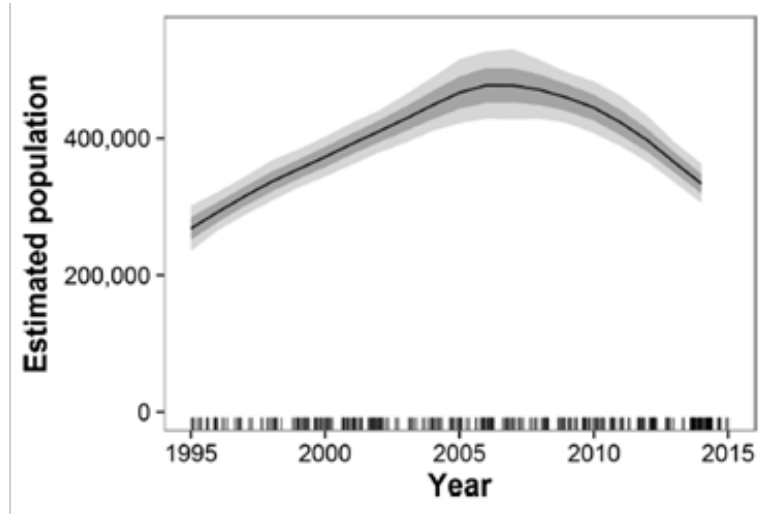

Figure 2 Africa's elephant population trend (Adapted from Chase MJ et al.,').

In Central Africa, more than $60 \%$ of elephants have been lost in the past 15 years. ${ }^{9}$ The countries of Central African Republic and Somalia have completely lost their elephant populations. ${ }^{7}$ This situation has occurred in spite of the presence of mechanisms to prevent biodiversity loss. ${ }^{10}$ Consequently, the African elephant has recently been listed as vulnerable on the International Union for Conservation of Nature Red List. ${ }^{4}$ Numerous factors jeopardize elephants' survival and affecting their conservation across Africa, with variations depending on the region in question. ${ }^{4}$ For example, high levels of poaching have been reported in Central Africa, while in Western Africa habitat loss constitutes a significant threat to elephant survival. In Southern Africa, climate change represents a major issue for livestock ${ }^{11}$ and wildlife survival. ${ }^{12}$ This literature review aims to elucidate the future of Africa's elephant populations, with particular emphasis placed on human-elephant conflict, habitat loss, climate change, and poaching, as well as highlighting some mechanisms that may help preserve the species.

\section{Threats to the elephant population}

\section{Human-elephant conflict}

Human-elephant conflict (HEC) is a significant concern in the conservation of species such as elephants and rhinos. ${ }^{13}$ Nevertheless, it has received relatively little attention from managers, conservationists and policy-makers due to the perceived salience of poaching. ${ }^{7}$ According to Dueveiller et al., ${ }^{14}$ HEC occurs when human actions cause an adverse effect on elephants, or vice versa. However, in a practical perspective, no contestation can truly occur between animals and humans because animals cannot consciously engage in such a conflict. Redpath et al. ${ }^{15}$ have described HEC: i) as an impact dealing with the direct interaction between animals and humans; and ii) as a conflict centered on human interactions between those seeking to conserve species and those who do not care or who do not understand the value of conserving animal species.

When elephants' activities intersect with those of humans, they can pose a serious problem. ${ }^{16}$ For instance, when elephants compete with humans for space and resources, significant conflict can arise. ${ }^{17}$ When HEC occurs, not only is there a risk of property loss, but human safety may also be jeopardized. ${ }^{18}$ Worldwide, numerous cases have been described of people being killed by elephants, with HEC the principal suspect. For instance, the Indian newspaper the Guardian has reported of 15 people being trampled and killed by a single elephant in India. Moreover, in response, most of the people affected demanded that the elephant be killed. The HEC issue is expected to increase with the growth of the human population in Africa.

HEC might also have an adverse effect on elephants. For example, when elephants migrate to areas settled by humans, they may become vulnerable to predation or poaching. ${ }^{19}$ Consequently, elephants generally prefer places with fewer human activities. ${ }^{20}$ Nevertheless, they require large amounts of space - preferably \pm 50 hectares per elephant-as they tend to graze and browse large quantities of grass and forages and require sufficient water and food.

The primary cause of HEC is generally considered competition between domestic livestock and elephants for space for water and grazing areas. ${ }^{20}$ Indeed, in general, domestic livestock (especially cattle) graze on veld during the day and are confined in a kraal at night. ${ }^{21}$ When they graze during the day, they tend to be guided by headers. However, during the night elephants use the darkness to search for food and may be shot by farmers where they affect crops. ${ }^{22}$

\section{Habitat loss}

Habitat loss constitutes a pertinent conservation issue. ${ }^{23}$ However, it has received less attention from conservationists, elephant managers and policy-makers due to the relative importance of the recent upsurge in poaching. ${ }^{7}$ Forestry feeds wildlife and contains more than $50 \%$ of plant species, rendering it the most important pillar in the ecosystem. ${ }^{24}$ The reported overexploitation of forestry ${ }^{24}$ raises numerous questions regarding the survival of wildlife. ${ }^{14}$ In 2007, the land available for wildlife declined to $\pm 15 \% .^{3}$ Indeed, between 2007 and 2015, a substantial decrease of 52 to $82 \%$ in Africa was reported. ${ }^{7}$ Habitat destruction has been closely associated with human population increase in many areas. ${ }^{13,25,26}$ West Africa represents a major site of habitat loss because many of its countries are seeing increased pressure placed on natural areas for mining, logging and the transformation of land for agricultural use. ${ }^{7}$ In Southern African countries such as Botswana, habitat loss is less pronounced ${ }^{2}$ due to small human populations and vast land availability, which can accommodate both humans and wildlife.

Elephants are losing to human population increase in the battle for space. ${ }^{19,27}$ They tend to be restricted to living in the center of forests in order to avoid attacks from humans, including for the purpose of poaching and resource exploitation. ${ }^{2}$ Furthermore, they require large amounts of high-quality core forest soil. ${ }^{28}$ When a forest is deforested, the thin, nutrient-rich soil is washed away, and it can take up to 50 years to recover. ${ }^{23,29}$ Hence, habitat destruction will become a longterm threat to wildlife survival. ${ }^{2}$ 


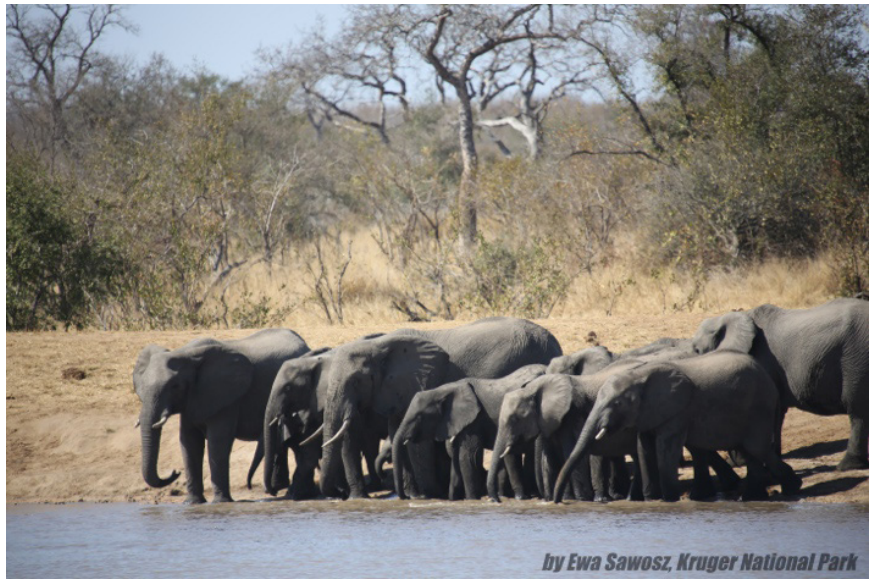

\section{Climate change}

Initially, climate change was associated with natural processes such as the circulation of oceanic currents. ${ }^{29}$ However, today it is increasingly believed that human activities such as fossil fuel combustion, deforestation and industrial activities cause climate change ${ }^{30}$ High temperatures affect animals in different ways, but such changes are particularly severe for those that cannot dissipate heat easily, such as elephants.

High temperatures: Many species of mammals use sweat glands or pant to cool down when air temperatures are high. However, elephants do not have a sweat duct, ${ }^{31}$ rendering heat dissipation a major issue. ${ }^{32}$ When temperatures are high, they must use non-evaporative techniques ${ }^{11}$ such as flapping their ears in order to maximize heat transfer..$^{32}$ They may also use behavioral strategies such as hiding in shaded areas under trees. ${ }^{31}$

Drought: Elephants' lives are contingent on the availability of water. ${ }^{11}$ Elephants tend to congregate in areas with sufficient water to drink and in which to bathe and play, especially in coastal lowlands and along river valleys. ${ }^{33}$ This is essential because they require a large amount of water, about 150-300 liters of water per day. During drought events, elephants may die due to limited amounts of water availability. ${ }^{32}$ Nevertheless, the effects of drought tend to be less severe for desert-adapted elephants, such as those found in northern Namibia and Central Africa.

Interaction between climate change and HEC: Climate change may enhance conflict between humans and elephants as they must compete for increasingly limited land, water and other natural resources. Moreover, climate change may stimulate humans to alter their living patterns and livelihoods. For example, increased vulnerability to flooding may cause people to move and establish new settlements in elephants' habitats. Droughts may equally cause people to migrate to other areas in search of food, fodder and water both for themselves and for their livestock. In seasons with limited rainfall, pasture fertility may be low and so fodder reserves for livestock are also constrained. ${ }^{34}$ When farmers run out of fodder, they often seek grazing areas elsewhere, especially in forests, which is where many elephants live.

\section{Elephant poaching}

Poaching can be defined as the illegal killing of wildlife animals. ${ }^{11}$ According to CITES, ${ }^{9}$ poaching is a major and growing threat to elephant populations (Figure 3). Indeed, the increase in the illegal trade of wildlife products has driven biodiversity loss among elephants. ${ }^{6}$

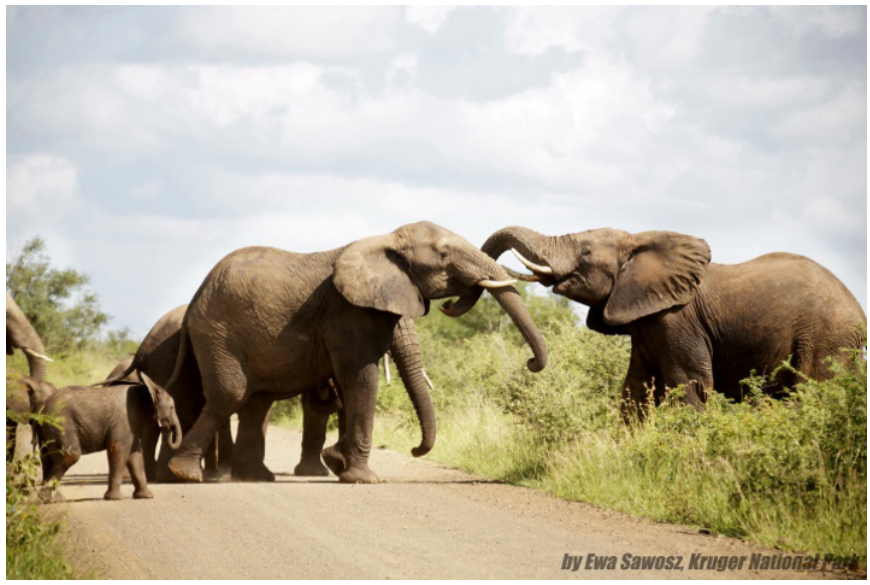

Africa

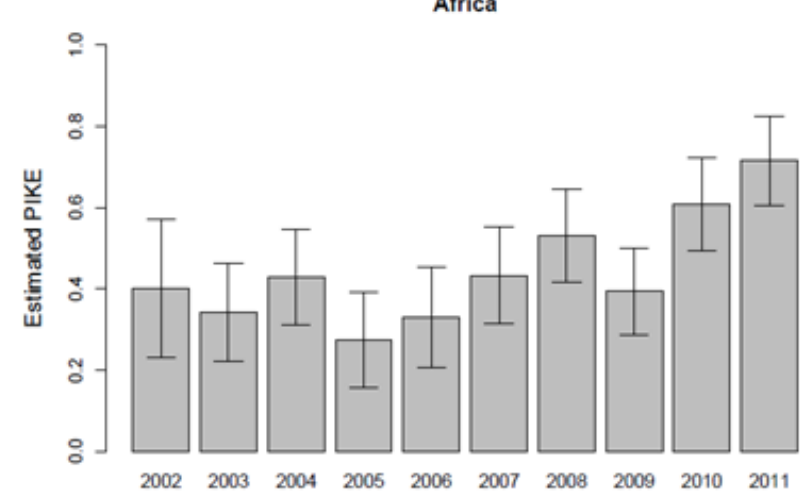

Figure 3 Estimated illegal killing of elephants by poaching (PIKE) from 2002 to $201 \mathrm{I}$ in Africa (Adapted from CITES ${ }^{9}$ ).

Numerous factors drive wildlife poaching, particularly of elephants, ${ }^{2,35}$ including poverty and ivory and crop raiding.

Poaching driven by poverty: The overhunting of wildlife for human consumption is well-documented and has resulted in the decline and extinction of certain species. ${ }^{5}$ It appears to be connected in part to poverty. ${ }^{36}$ Tusks tend to be particularly prized. ${ }^{2}$ Therefore, elephant poaching should not be approached as a mere conservation concern, but rather as an issue of poverty and development. ${ }^{11}$

Poverty and wildlife conservation have been connected by Adams et al. ${ }^{36}$ in two important ways: i) poverty as the main constraint to wildlife conservation via overhunting and poaching as a source of income; and ii) attempts to reduce poverty in most African countries are dependent on living animals, particularly wildlife animals.

\section{Poaching for ivory}

Elephant populations face high risks of extinction due to the ivory trade. ${ }^{38}$ The majority of illegally killed elephants are found without their tusks. ${ }^{2}$ For example, in Niokola-Koba National Park in Senegal, the elephant population reached a maximum of 450 in 1979 before drastically dropping to about 80 in 1984 . The primary cause of decline was ivory poaching by well-armed poachers. ${ }^{37}$ China is the largest trader of ivory, followed by Thailand, and African elephants' tusks are especially common. ${ }^{2}$

\section{Crop raiding}

Killing represents a 'quick fix' method that is primarily used in 
Africa by elephant authorities or affected people. ${ }^{38}$ In South Africa, and especially in the Eastern Cape, elephants have been killed so that they do not exceed certain numbers ${ }^{33}$ and trample crops. The issue is that within an elephant population, it is difficult to identify a particular

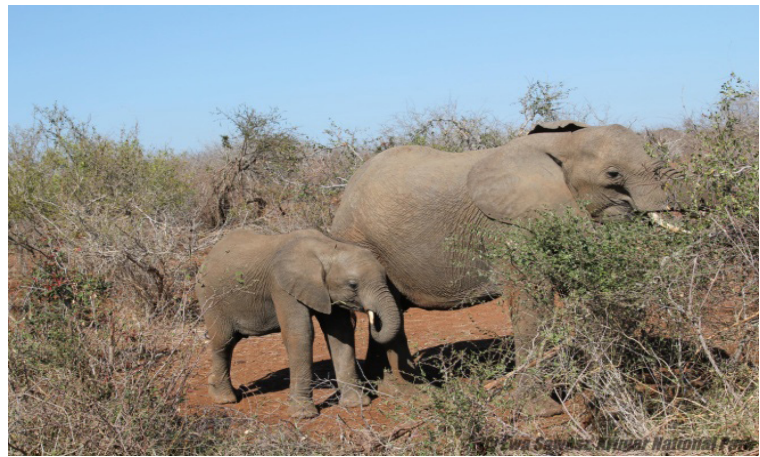

\section{What can be done?}

Numerous measures can be taken to assist elephants in coping with a changing climate. These include safeguarding elephants' access to water sources, whether natural or artificial. Elephants require space in which to roam, find food and water as well as other elephants for mating. Thus, securing land for elephants and enabling them to move between them, in some cases across national borders, is necessary.

Deforestation is caused by imprudent land use as well as the expansion of industrial areas. ${ }^{28}$ In Africa, the unregulated building of shacks cannot be ignored. Therefore, organizations such as the Food and Agriculture Organization (FAO) should put mechanisms in place to minimize deforestation. For instance, effective measures for the management of deforestation and the practice of afforestation are yet to be implemented.

It is also important to reduce pressure on elephants' habitats. This may be achieved by supporting community livelihood activities to enable people to cope during livestock food shortages, such as assisting in rangeland management to conserve fodder for livestock so that cattle do not need to be grazed in pastures used by elephants. Improvements to agricultural practices should also be made through sustainable agriculture. Working with communities to undertake land-use planning increases the space available for their activities, including for livestock and agriculture as well as for elephants and other wildlife. culprit. In many cases, the wrong elephant is killed, which fails to solve the problem. ${ }^{38}$ Even if the offender is killed, others potentially replace it. ${ }^{19}$

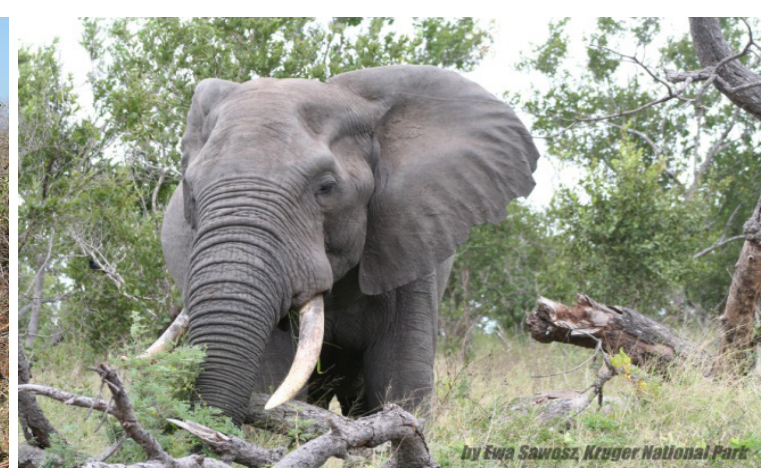

In the case of crop raiding, elephants should not be killed. This is because elephants are slow breeders. For instance, when an elephant is killed it will take 15 years for a female to replace it. Therefore, when raiding crops, elephants should either be denied food or given a place in which to live. ${ }^{38}$

Identifying the principal causes of elephant poaching is complex. However, it is well-acknowledged that China and Thailand are the largest ivory traders, ${ }^{2}$ and ivory tends to be transported from Kenya, Tanzania and South Africa. Therefore, improving and tightening law enforcement may play a significant role. For instance, collaborations between the military, anti-poacher units and the police may help fight poachers, ${ }^{2}$ and boost the elephant population in regions such as Southern Africa. ${ }^{1}$ A similar strategy should also be implemented in Western, Central and Eastern African regions, where poaching represents a principal cause of elephants' decline. Nevertheless, highly trained anti-poachers will be required, necessitating considerable financial resources.

Elephants may also benefit poor people living close to wildlife parks through the development of tourism. ${ }^{39}$ Policy-makers, managers and wildlife conservationists should develop sustainable means of including elephants in tourism so that their conservation will be guaranteed. ${ }^{40,41}$

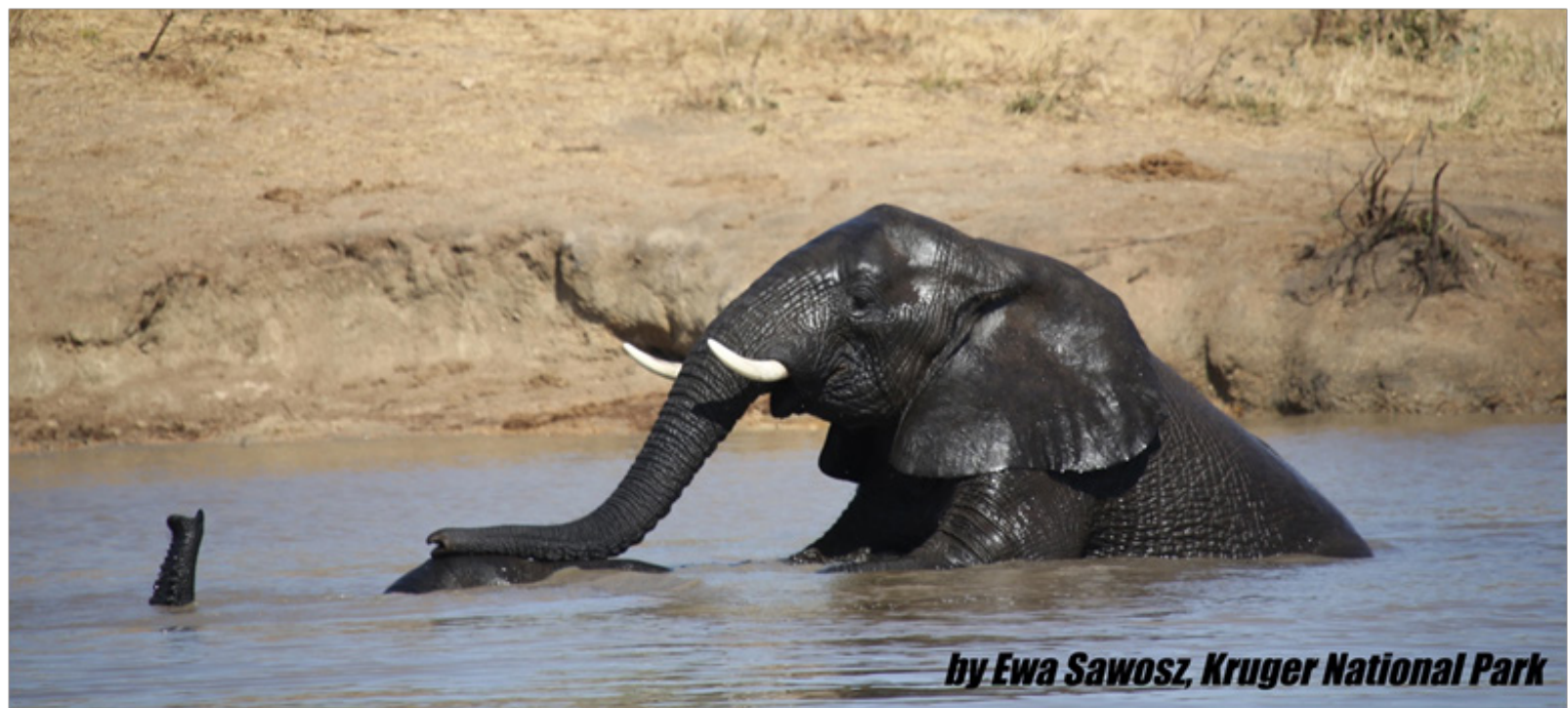

Citation: Ngcobo JN, Nedambale TL, Nephawe KA, et al.The future survival of African elephants: implications for conservation. Int J Avian \& Wildlife Biol. 2018;3(5):379-384. DOI: 10.15406/ijawb.2018.03.00I23 


\section{Conclusion}

Elephants will soon become extinct if no proper conservation strategies are implemented. This review has revealed that elephant do not only face issues of poaching, but also habitat loss and climate change connected with human activities. When all of these factors are combined, they are capable of eradicating elephant populations across Africa. This issue is particularly pertinent because Africa is comprised of poor and developing countries. In most cases, the development strategy is to expand industrial areas and agriculture in order to create new job opportunities. More roads continue to be built and people continue to move from rural to urban areas in search of superior jobs and lifestyles. This alone may lead to elephants' extinction through habitat loss and global warming. People still need to be educated about the value of elephants. However, given that many people in Africa are illiterate, this will constitute a significant challenge and will require considerable financial resources. Therefore, developed countries as well as organizations such as the FAO and the United Nations might play an important financial role.

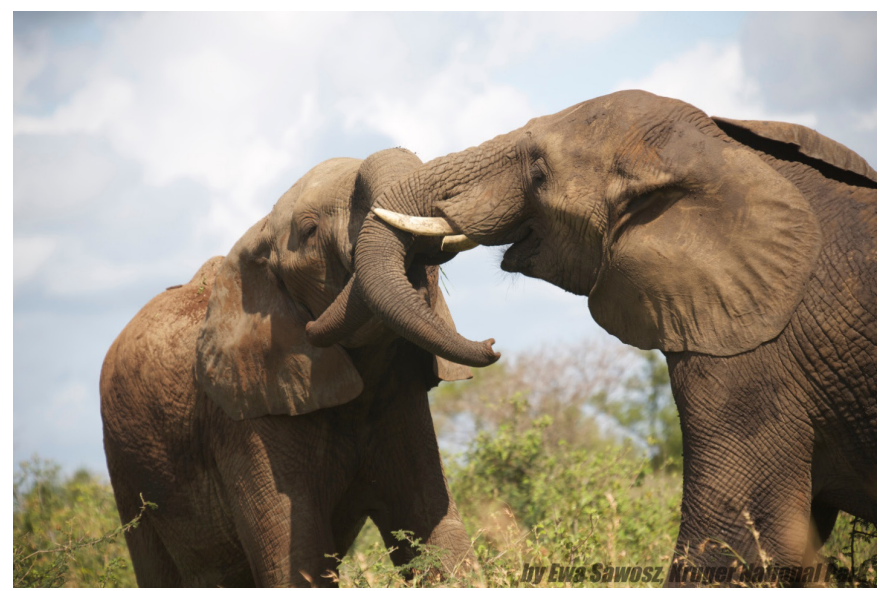

\section{Acknowledgements}

The authors would like to express their gratitude to the Erasmus+ Program at the Warsaw University of Life Sciences for providing the course in Wildlife Biology and Conservation.

\section{Conflicts of interest}

The authors declare no conflicts of interest.

\section{References}

1. Chase MJ, Schlossberg S, Griffin CR, et al. Continent-wide survey reveals massive decline in African savannah elephants. Peer J. 2016; $4: \mathrm{e} 2354$

2. Nelleman C, Formo RK, Blanc J, et al. Elephants in the dust-the African elephant crisis. A rapid response assessment. United Nations Environment Programme, GRID-Arendal. 2013.

3. Blanc JJ, Barnes RFW, Craig GC, et al. African Elephant Status Report: An update from the African Elephant Database. The World Conservation Union. 2007.

4. Blanc JJ, Thouless CR, Hart JA, et al. African Elephant Status Report 2002: An update from the African Elephant Database. IUCN/SSC African Elephant Specialist Group. Gland (Switzerland). 2003.

5. Wittemyer G, Northrup JM, Blanc J, et al. llegal killing for ivory drives global decline in African elephants. Panas. 2014.
6. Beale CM, Hauenstein S, Mduma S, et al. Spatial analysis of aerial survey data reveals correlates of elephant carcasses. Biological Conservation. 2018;218:258-267.

7. Thouless CR, Dublin HT, Blanc JJ, et al. African elephant status report 2016: An update from the African elephant database. Ocassional paper of the IUCN species survival commission no. 60. 2016.

8. Van Kooten GC. Protecting the African elephant: A dynamic bioeconomic model of ivory trade. Biological Conservation. 2008; 141:2012-2022.

9. CITES. 13th Meeting of the Conference of the Parties to CITES. Switzerland: Global Species Programme, WWF factsheet; 2004.

10. Pimm SL, Jenkins CN, Abell R, et al. The biodiversity of species and their rates of extinction, distribution, and protection. Biodiversity status. 2014;344:987-996.

11. Dunkin RC, Wilson D, Way N, et al. Climate influences thermal balance and water use in African and Asian elephants: physiology can predict drivers of elephant distribution. Journal of Experimental Biology. 2013;216:2939-2952.

12. Harvell D, Altizer S, Cattadori IM, et al. Climate change and wildlife diseases: When does the host matter the most? Ecological Society of America. 2009;90:912-920.

13. Theuerkauf J, Ellenberg H, Waitkuwait WE, Mühlenberg M. Forest elephant distribution and habitat use in the Bossematié forest reserve, Ivory Coast. Pachyderm. 2001;30:2001:37-43.

14. Duveiller G, Defourny P, Desclée B, et al. Deforestation in Central Africa: estimates at regional, national and landscape levels by advanced processing of systematically-distributed Landsat extracts. Small Ruminant Research. 2008;112:1969-1981.

15. Redpath SM, Young J, Evely A, et al. Understanding and managing conservation conflicts. Trends in Ecology \& Evolution. 2013;28:100 109

16. Treves A, Wallace RB, Naughton-Treves L, Morales A. Co-managing human-wildlife conflicts: A review. Journal of Human Dimensions of Wildlife. 2006;11:383-396.

17. Pimm SL, Russell GJ, Gittleman JL, et al. The future of biodiversity. Science, ProQuest Health and Medical Complete. 1995;347-350.

18. Choudhury A. Human-elephant conflicts in Northeast India. Journal of Human Dimensions of Wildlife. 2004;9:261-270.

19. Hoare R. Management implications of new research on problem elephants. Pachyderm. 2001;30:44-48.

20. Graham MD, Douglas-Hamilton I, Adams WM, et al. The movement of African elephants in a human-dominated land-use mosaic. Journal of Animal Conservation. 2009; 12:445-455.

21. Mavule BS, Muchenje V, Kunene NW. Characterization of Zulu sheep production system: Implications for conservation and improvement. Academic Journal of Scientific Research and Essay. 2013;8(26):12261238.

22. Sitati NW, Walpole MJ, Leader-Williams N. Factors affecting susceptibility of farms to crop raiding by African elephants: using a predictive model to mitigate conflict. Journal of Applied Ecology. 2005;42:1175-1182.

23. UNEP, CITES, IUCN, TRAFFIC. Elephants in the Dust-The African Elephant Crisis. A Rapid Response Assessment. United Nations Environment Programme, GRID-Arendal. 2013.

24. Mayaux P, Holmgren P, Achard F, et al. Tropical forest cover change in the 1990s and options for future monitoring. Philosophical Transaction of Royal Society. 2005;360:373-384 
25. Bandara R, Tisdell C. Comparison of rural and urban attitudes to the conservation of Asian elephants in Sri Lanka: empirical evidence. Biological Conservation. 2003;113:327-342.

26. Neupane D, Kunwar S, Bohara AK, Risch TS. Willingness to pay for mitigating human-elephant conflict by residents of Nepal. Journal for Nature Conservation. 2017;36:65-76.

27. Kansky R, Knight AT. Key factors driving the attitudes towards large mammals in conflict with humans. Biological Conservation. 2014;179:93-105.

28. Kinnaird MF, Sanderson ER, O'Brien TG, et al. Deforestation trends in a tropical landscape and implications for endangered large mammals. Conservation Biology. 2003;17:245-257.

29. Patz JA, Graczyk TK, Geller N, et al. Effects of environmental change on emerging parasitic diseases. Int J Parasitol. 2000;30:1395-1405.

30. Shine KP. Radiative forcing of climate change. Space science review. 2000;94:363-373.

31. Wright PG. Why do elephants flap their ears? South African Journal of Zoology. 1984;19:266-269.

32. Williams TM. Heat transfer in elephants: thermal partitioning based on skin temperature profiles. Zoological Society of London. 1990;222:235245 .

33. Kerley GIM, Landman M. The impacts of elephants on biodiversity in the Eastern Cape Subtropical Thickets. South African Journal of Science. 2006;102:395-402.
34. Toulmin C. Drought and the farming sector: Loss of farm animals and post-drought rehabilitation. African livestock policy analysis network, International livestock Centre for Africa, Addis Ababa, Ethiopia. 1986.

35. Duffy R, ST John FAV, Büscher B, et al. Toward a new understanding of the links between poverty and illegal wildlife hunting. Conservation Biology. 2016;30(1):14-22.

36. Adams WM, Aveling R, Brokington D, et al. Biodiversity conservation and the eradication of poverty. Science. 2004;303:1146-1149.

37. Bouche P, Douglas-Hamilton I, Wittemyer G, et al. Will elephants soon disappear from West African Savannahs? Plos One. 2011.

38. Hoare RE, Du Toit JT. Co-existence between people and elephants in African savannahs. Society for Conservation Biology. 1999;13:633-639.

39. Whyte I, Van Aarde R, Pimm SL. Managing the elephants of Kruger National Park. Animal Conservation. 1998;1:77-83.

40. Maisels F, Strindberg S, Blake S, et al. Devastating decline of forest elephants in Central Africa. PLoS One. 2013.

41. Redpath SM, Young J, Evely A, et al. Understanding and managing conservation conflicts. Trends in Ecology \& Evolution. 2013;28:100109. 